\title{
Kinematic Analysis on Athletes' Take-off Skill in Half-pipe Snowboarding
}

\author{
Xin Wang ${ }^{1, a}$ \\ ${ }^{1}$ School of Kinesiology, Shenyang Sport University, Shenyang 110102, Liaoning, \\ China ashin_wang@163.com
}

Key words: Take-off; Half-pipe Snowboarding; Kinematic Analysis; Joint angle

\begin{abstract}
Take-off skill is one of the most important part in half-pipe snowboarding which directly determined the flying height, flying time, even the quality of motion. Study on the kinematic parameters of take-off stage of some master-standard athletes for the purpose of researching on the factors influencing the take-off skill by means of literature review, biomechanics theory, the movement-image analysis, statistics, expert interviews as well as combining the characteristics of this event. The results shows that gravity velocity, joint angle, angle and speed between board and horizontal level will have some influence on take-off skill. Suggestions are made that body should be well positioned before take-off; the center of the gravity position should be well controlled; the effective take-off angle should be kept effectively.
\end{abstract}

\section{Introduction}

The technology of half-pipe snowboarding includes the four stages of sliding, take-off, flying and landing. The height of take-off restrains motion time, difficulty of motion completion, motion variety as well as motion quality. Flight height is the key factor influencing other elements. Through theoretical and empirical research, factors affecting the take-off speed of half-pipe snowboarding were analyzed to improve technical service, provide focus of explaining the provision and technical features of the event and references to athletes and coaches and further improve the technical content of training as well as the quality of training.

\section{Methods}

\subsection{Subjects}

Some elite half-pipe athletes of Chinese team were chosen and the action is Regular 720 degree.

\subsection{Procedure}

Three video cameras were used to shoot athletes' training from fixed points of front and side positions. APAS System was used to analyze athletes' training action video. Kinematic indexes obtained were processed by SPSS13.5.

\section{Results}

3.1 Analysis of joints Angle

Table 1 Men's Regular $720^{\circ}$ Change of Posture Angle at the End of tale-off

\begin{tabular}{cccc}
\hline Angle Parameters & Success $\left.^{\circ}{ }^{\circ}\right)$ & Failure $\left({ }^{\circ}\right)$ & P Value \\
Left Knee Joint & $135.26 \pm 23.00$ & $102.20 \pm 12.37$ & 0.038 \\
Right Knee Joint & $136.51 \pm 39.46$ & $108.19 \pm 20.94$ & 0.011 \\
Left Hip Joint & $115.16 \pm 32.97$ & $138.46 \pm 15.18$ & 0.005 \\
Right Hip Joint & $145.89 \pm 29.22$ & $120.65 \pm 17.94$ & 0.043 \\
Left Shoulder Joint & $69.69 \pm 30.89$ & $40.02 \pm 26.98$ & 0.029 \\
Right Shoulder Joint & $94.22 \pm 43.83$ & $94.42 \pm 36.10$ & 0.992 \\
Left Elbow Joint Angle & $166.31 \pm 12.29$ & $159.70 \pm 14.66$ & 0.376 \\
Right Elbow Joint Angle & $148.63 \pm 30.52$ & $153.30 \pm 14.97$ & 0.738 \\
\hline
\end{tabular}

Table 1 shows the change of posture angle at the end of tale-off of men's regular $720^{\circ}$. The joint angles of both knees are successfully controlled between $136.56^{\circ} \pm 32.48^{\circ}$ and $102.54^{\circ}$ $\pm 28.37^{\circ}$. There is significant difference between success and failure in knee joint angle and hip joint 
angle. The proper joint angle is the decisive factor that affects sliding and take-off. Too small joint angle may cause tension of athletes' muscles, which will produce braking effects after take-off and affect take-off velocity. On the contrary, too large angle will raise gravity center, which is harmful to the successful performance of balance keeping and sliding.

3.2 Analysis of take-off velocity

Table 2 Men's Regular $720^{\circ}$ Change of Linear Indexes at the End of tale-off

\begin{tabular}{lccc}
\hline Parameters & Success(m) & Failure $(\mathrm{m})$ & P Value \\
\hline $\begin{array}{l}\text { Horizontal coordinate of gravity } \\
\text { center }\end{array}$ & $1.47 \pm 3.33$ & $1.60 \pm 4.69$ & 0.499 \\
$\begin{array}{l}\text { Vertical coordinate of gravity } \\
\text { center }\end{array}$ & $1.81 \pm 1.24$ & $0.85 \pm 0.77$ & 0.477 \\
$\begin{array}{l}\text { Horizontal velocity of gravity } \\
\text { center }\end{array}$ & $1.46 \pm 6.74$ & $-1.15 \pm 5.26$ & 0.383 \\
$\begin{array}{l}\text { Vertical coordinate of gravity } \\
\text { center }\end{array}$ & $5.00 \pm 5.96$ & $0.21 \pm 2.87$ & 0.021 \\
$\begin{array}{l}\text { Gravity center joint velocity(m/s) } \\
\text { ravity }\end{array}$ & $9.47 \pm 3.58$ & $5.16 \pm 2.54$ & 0.001 \\
\hline
\end{tabular}

Table 2 shows the change of linear indexes of men's regular $720^{\circ}$ at the end of tale-off. We can see from the table that the success or failure of the actions before the end of take-off correlates with gravity velocity. There is significant difference in horizontal and vertical velocity of gravity center and joint velocity $(\mathrm{P}<0.05)$.

We can see from Table 4 that the success of take-off is closely related to gravity center velocity, no matter be it vertical, horizontal or joint velocity of gravity center, each value of these parameter at the end of take-off are larger than that of the beginning. The velocity will decide flight height an flight duration. The decrease of take-off velocity will reduce the flight height, and the loss of height in turn caused the loss of flight time. Without enough time in the air, the supposed jump forms cant not be completed and thus affected the time of landing as well as the performance of next flight. All these will affect the athlete's performance and their challenge of difficulty. The low quality of the performance will sure get a lower soccer in the game. Before take-off, sliding takes up most of the time. So sliding technique is the guarantee of successful take-off. Without good sliding technique, the athlete cannot obtain desired take-off velocity and flight height. Equally, only perfect sliding and take-off technique can lead to proper flight height and flight time.

3.3Analysis of snowboard and velocity-horizontal level angle

Table 3 Men's Regular $720^{\circ}$ Change of Evaluation Indexes at the End of tale-off

\begin{tabular}{|c|c|c|c|}
\hline Parameters & Success & Failure & $\mathrm{P}$ \\
\hline $\begin{array}{l}\text { Distance between hip joint and snowboard } \\
\text { (m) }\end{array}$ & $0.69 \pm 0.19$ & $0.68 \pm 0.18$ & 0.378 \\
\hline $\begin{array}{l}\text { Distance between gravity center and } \\
\text { snowboard(m) }\end{array}$ & $0.72 \pm 0.10$ & $0.67 \pm 0.05$ & 0.24 \\
\hline Joint velocity and horizontal level angle $\left(^{\circ}\right.$ ) & $58.89 \pm 34.51$ & $\begin{array}{c}73.40 \\
\pm 41.32\end{array}$ & 0.003 \\
\hline Snowboard and horizontal level angle $\left(^{\circ}\right.$ ) & $65.03 \pm 54.94$ & $83.50 \pm 8.83$ & 0.032 \\
\hline Left shank and snowboard Angle $\left({ }^{\circ}\right)$ & $83.74 \pm 30.94$ & $\begin{array}{c}88.99 \\
\pm 21.40\end{array}$ & 0.729 \\
\hline Right shank and snowboard Angle $\left(^{\circ}\right.$ ) & $111.27 \pm 12.89$ & $\begin{array}{c}94.82 \\
\pm 28.20\end{array}$ & 0.167 \\
\hline
\end{tabular}

Table 3 shows the change of evaluation indexes men's regular $720^{\circ}$ at the end of tale-off. There 
is no significant difference between success and failure in leg-snowboard angle, distance between hip joint and snowboard center, while there is significant difference in the angle between snowboard and horizontal velocity $(\mathrm{p}<0.05)$.

We can see from Table 3 that gravity center and the angle between speed and horizontal level have obvious effect the success of actions at the end of take-off. At the moment of take-off, the front part of snowboard loses its support, the point of load moves away from the snowboard center to the back, which is always on the pipe. After the sliding out of the front foot, the back foot should step against the board forcefully so as to gain the reaction power to maintain balance and keep a smooth parabola and increase take-off velocity and ensure a proper take-off angle. At the end of take-off, the range of knee joint angle and hip joint angle are all larger than that of the beginning. Joint angle affects body gravity center, which is one of the factors influencing take-off velocity. When body gravity center is close to the front part of the snowboard, the take-off velocity increases and is close to the range of success. On the contrary, the sliding distance will be shortened and it is bad for balance keeping.

\section{Conclusion}

4.1Take-off technique is affected by knee joint angle, hip joint angle, horizontal velocity of gravity center, vertical velocity of gravity center, joint velocity of gravity center, angle of joint velocity and horizontal level, angle of snowboard and horizontal level.

4.2 The position of gravity center affects the quality of take-off. When body gravity center is close to the front part of the snowboard, the take-off velocity increases and is close to the range of success.

4.3 The key of half-pipe skill lie is take-off and sliding is the foundation of take-off.

4.4 Trunk angle affects take-off velocity. Different half-pipe fields also have different influence on take-off.

\section{Acknowledgments}

This work was financially supported by the important research in Shenyang Sport University(XKFX1503).

\section{References}

[1] Wang Baoheng, Technologies of Women Half-pipe Snowboard of First Three Athletes Between the 11th Winter Olympic Games with Turin Winter Olympic Games, Journal of Shenyang Sport University, 2008, (02)

[2] Fan Chunlai, An Linbin, LuoYongsheng. Countermeasure on the Sustainable Development of Chinese Half-pipe Snowboard Event [J] China Winter Sports, 2008( 3):23-25

[3] Li Shuyuan, The Development and Application of Group Training Theory on China Single Board Sport [J]China Winter Sports 2008( 3):46-48

[4] Yan Hongguang, Liu Ping, Guofeng, Factors Influencing Velocity Away from Decks in Snowboard Half-pipe [J]. Journal of Shenyang Sport University. 2009, 28 (3): 10-18

[5] Tian Xiaojian, Chen Weiguang, Technical Analysis of Take-off Phase of Snowboard Half-pipe [J] Journal of Ha'erbin Sport University 2005( 2): 125-127

[6] Wang Baoheng, A Consideration on Basic Sliding and Flight Height of Half-pipe Snowboard [J]. Journal of Shenyang Sport University, 2005 (2): 71-73 